\title{
Comparison and optimisation of microRNA extraction from the plasma of healthy pregnant women
}

\author{
VICTORIA L. PARKER ${ }^{1}$, BRYONY F. CUSHEN ${ }^{1}$, ELEFTHERIOS GAVRIIL ${ }^{1}$, BENJAMIN MARSHALL ${ }^{1}$, \\ SARAH WAITE ${ }^{1}$, ALLAN PACEY $^{1}$ and PAUL R. HEATH ${ }^{2}$ \\ ${ }^{1}$ Department of Oncology and Metabolism, The University of Sheffield, Sheffield S10 2SF; \\ ${ }^{2}$ Sheffield Institute of Translational Neuroscience, The University of Sheffield, Sheffield S10 2HQ, UK
}

Received July 25, 2020; Accepted December 15, 2020

DOI: $10.3892 / \mathrm{mmr} .2021 .11897$

\begin{abstract}
Circulating microRNA (miRNA) biomarkers are implicated in the diagnosis, monitoring and prediction of various disease processes. Before embarking upon biomarker discovery, miRNA extraction techniques must first be optimised in the biofluid and population under study. Using plasma from a healthy pregnant woman, it was attempted to optimise and compare the performance of two commercially available miRNA extraction kits; Qiagen (miRNeasy Serum/Plasma) and Promega (Maxwell $^{\circledR}$ RSC miRNA from Tissue or Plasma or Serum). Sample miRNA content (concentration and percentage) was assessed using Agilent Bioanalyzer Small RNA chips and reverse transcription-quantitative PCR (RT-qPCR) using four constitutively expressed miRNAs (hsa-miR-222-3p, hsa-let-7i-3p, hsa-miR-148-3p and hsa-miR-30e-5p). Quality control spike-ins monitored RNA extraction (UniSp2, 4 and 5) and cDNA synthesis (UniSp6, cel-miR-39-3p) efficiency. Optimisation approaches included: i) Starting volume of plasma; the addition of ii) Proteinase K; iii) a RNA bacteriophage carrier (MS2); and iv) a glycogen carrier. The two kits exhibited equivalence in terms of miRNA recovery based on Bioanalyzer and RT-qPCR $\Delta \Delta \mathrm{Cq}$ results. Optimisation attempts for both kits failed to improve upon miRNA content compared with standard methodology. Comparing the standard methodology, the Qiagen kit was more consistent (smaller variance of $\Delta \mathrm{Cq}$ values) compared with the Promega kit. The standard methodology of either kit would be suitable for the investigation of miRNA biomarkers in a healthy pregnant population.
\end{abstract}

\section{Introduction}

MicroRNA (miRNA) are a class of short, non-coding RNAs involved in post-transcriptional downregulation of protein

Correspondence to: Dr Victoria L. Parker, Department of Oncology and Metabolism, The University of Sheffield, Level 4, The Jessop Wing, Tree Root Walk, Sheffield S10 2SF, UK

E-mail:v.parker@sheffield.ac.uk

Key words: microRNA, Homo sapiens, extraction, optimisation, pregnancy, women expression in eukaryotic organisms, through silencing of target messenger RNAs (1-3). They are implicated in regulating approximately one third of the genome; controlling multiple cellular processes, including apoptosis (2-4), proliferation (2), differentiation (2-5) and development (3-6).

An expanding body of pre-clinical evidence has implicated altered miRNA expression profiles in several disease processes (2,5-10), with the potential to facilitate earlier diagnosis, disease monitoring and predict prognosis (3,8-10). Increasing literature is emerging concerning the role of placental-derived miRNAs in pregnancy, originating from three main clusters on chromosome 19 (C19MC, miR-371-3) and chromosome 14 (C14MC) (11,12). Altered miRNA profiles have been detected in both healthy pregnancy (changing across trimesters and compared to the non-pregnant state) (13-16) and pregnancies complicated by gestational hypertension $(17,18)$, pre-eclampsia (19), diabetes $(20,21)$ or congenital anomalies (22).

Given the potential clinical utility of miRNAs, accurate and efficient quantification is essential. The relative ease and safety of obtaining blood samples over tissue biopsies (23-25), as well as the stability of circulating miRNAs has focused much of the current research towards blood testing $(3,26)$. However, due to the low concentration of free miRNAs in biofluids, variable findings between different starting media (serum vs. plasma) and the alteration of the miRNA profile by haemolysis, signalling or environmental exposures, robust results have proven difficult to obtain (26-30). Additionally, variability in the collection, storage and processing of samples can affect outcomes (27). Standardised procedures for all stages of miRNA quantification would minimise variability but are yet to be developed. Techniques that increase efficiency are favoured, as higher miRNA concentrations in the eluate facilitate quantification (27,31). miRNA extraction from biofluids is the prime source of intra-assay variation in miRNA quantification, highlighting the need for a robust, reproducible protocol (32-34).

To assist in miRNA extraction, there are several commercially available kits, yet many pre-clinical biomarker studies fail to acknowledge the variability introduced by these different methodologies, potentially contributing to poor replicability between studies and delaying progression into clinical practice. There is a paucity of literature concerning the optimal kit to answer the clinical question at hand, as media and kit 
performance may vary between the patient population (males, females, pregnant or non-pregnant) and the disease state under investigation $(25,35)$. Compounded by inter-patient variability within study samples, identifying the optimal methodology is extremely difficult $(27,32,36,37)$. Factors including the starting volume of biofluid, use of glycogen, yeast or bacteriophage RNA carriers (e.g. MS2) and the addition of a serine protease (e.g. Proteinase K) to digest native proteins can all be modified to improve the yield and reproducibility of miRNA extraction (24); the effect of each being dependent on the extraction technique $(24,31,38-42)$. Carriers are particularly useful when handling biofluids with low starting miRNA concentrations (e.g. human serum and plasma), as counterproductively, the extraction process itself loses a sizeable proportion of the sample miRNA content (39). Downstream analysis techniques may restrict the choice of carrier, as degraded RNA bacteriophages cannot be distinguished from sample RNA content using Next Generation Sequencing platforms (43), hence miRNA-free glycogen carriers are instead recommended for this application (43).

This study aimed to compare the relative efficiency of two commercially available miRNA extraction kits to determine the most suitable approach using human plasma derived from women with an uncomplicated, healthy pregnancy. Qiagen miRNeasy Serum/Plasma kit uses a well-known chloroform/phenol and column-based miRNA extraction system, whilst the Promega Maxwell $^{\circledR}$ RSC miRNA from Tissue or Plasma or Serum kit employs a novel technique involving an automated paramagnetic particle mover to drive the RNA through binding, washing and elution steps. To our knowledge, in the published literature, a methodological investigation involving this patient group has never been performed, neither has a comparison of these two particular extraction kits. We additionally sought to optimise the performance of each kit through four methodological modifications varying the: (i) starting volume of plasma; the addition of (ii) Proteinase K; (iii) a RNA bacteriophage carrier (MS2); and (iv) a glycogen carrier.

\section{Materials and methods}

Sample collection. Blood was obtained from a healthy pregnant woman with an uncomplicated, low-risk pregnancy at 9 weeks' gestation using $4.5 \mathrm{ml}$ Sodium citrate vacutainer tubes (NHS Supply Chain). Standard venepuncture procedures were followed, according to the National Cancer Institute Early Detection Research Network, involving a 21-gauge needle to minimise haemolysis. Following collection, samples were kept upright and stored on ice (maintaining a temperature of $\sim 4^{\circ} \mathrm{C}$ ) to inhibit miRNA degradation by circulating RNases within whole blood and processed within $2 \mathrm{~h}$. Samples were centrifuged at $1,900 \times \mathrm{g}$ for $10 \mathrm{~min}$ at $4^{\circ} \mathrm{C}$ with the recovered plasma supernatant aliquoted and immediately stored at $-80^{\circ} \mathrm{C}$. Following gentle thawing at room temperature, aliquots underwent a second centrifugation step $(16,000 \mathrm{x} g$ for $10 \mathrm{~min}$ at $4^{\circ} \mathrm{C}$ ) to generate platelet poor plasma.

Ethical approval. Written patient consent was taken from participants, within the ethical approval obtained from the United Kingdom North East Newcastle and North Tyneside 1 NHS Research Ethics Committee (Reference 16/NE/0292) on
30/08/2016 and The Health Research Authority on 27/09/2016, with approved non-substantial (18/10/2018 and 01/05/2019) and substantial (12/12/2019) amendments (Table II).

miRNA extraction. miRNA was extracted from plasma samples using the: i) miRNeasy Serum/Plasma kit (217184; Qiagen) and ii) a prototype of the Maxwell ${ }^{\circledR}$ RSC miRNA from Tissue or Plasma or Serum kit (AS1680; Promega) (44) both with minor modifications. Standard manufacturer and optimised approaches were performed, modifying: i) starting volume of plasma; the addition of ii) Proteinase $\mathrm{K}$; iii) a RNA bacteriophage carrier (MS2); and iv) a glycogen carrier (Figs. 1 and 2; Table I). In short, step (2) of the miRNeasy protocol was modified; UniSp2, UniSp4 and UniSp5 spike-in mix (reconstituted according to manufacturers' instructions) (339390, RNA spike-in kit; Qiagen) (Table II) was diluted 1:11 into QIAzol lysis buffer, mixing thoroughly. $0.5 \mu \mathrm{l}$ of spike-in mix was added per $100 \mu \mathrm{l}$ of plasma in accordance with the manufacturer's protocol. When required (Fig. 2; Table I), $1 \mu \mathrm{g}$ per $200 \mu \mathrm{l}$ of RNA bacteriophage MS2 $(0.8 \mu \mathrm{g} / \mu \mathrm{l})$ (10165948001; Roche Diagnostics GmbH) or $2 \mu \mathrm{g}$ per $200 \mu \mathrm{l}$ of RNA grade Glycogen $(20 \mathrm{mg} / \mathrm{ml})$ (R0551; Thermo Fisher Scientific, Inc.) was added to the dilute RNA spike-in and QIAzol lysis reagent mix, combining thoroughly. This mix was combined with the remaining volume of lysis buffer and step (4) of the protocol omitted.

The prototype Promega protocol with minor modifications was conducted as follows: Lyophilised DNase I was resuspended with $275 \mu \mathrm{l}$ of nuclease free water, adding $5 \mu \mathrm{l}$ of Blue Dye as a visual indicator, inverting or swirling to mix. Aliquots were produced, storing at $4^{\circ} \mathrm{C}$ (few weeks) or $-20^{\circ} \mathrm{C}$ (longer storage). UniSp2, UniSp4 and UniSp5 spike-in mix (reconstituted according to manufacturers' instructions) (339390, RNA spike-in kit, Qiagen) was diluted $1: 11$ into binding buffer. $0.5 \mu \mathrm{l}$ of spike-in mix was added per $100 \mu \mathrm{l}$ of plasma in accordance with the manufacturer's protocol. When required (Fig. 2; Table I), $1 \mu \mathrm{g}$ per $200 \mu \mathrm{l}$ of RNA bacteriophage MS2 $(0.8 \mu \mathrm{g} / \mu \mathrm{l})$ (10165948001; Roche Diagnostics $\mathrm{GmbH}$ ) or $2 \mu \mathrm{g}$ per $200 \mu \mathrm{l}$ of RNA grade Glycogen (20 mg/ml) (R0551; Thermo Fisher Scientific, Inc.) was added to the diluted spike-in mix, combining thoroughly. The spike-in +/- carrier molecule mix was then added to the remaining volume of binding buffer, mixing thoroughly. 100, 200 or $500 \mu \mathrm{l}$ (Fig. 1; Table I) of pre-processed plasma (see Sample collection in Materials and methods section) was transferred to a $1.5 \mathrm{ml}$ Eppendorf and $60 \mu \mathrm{l}$ Proteinase $\mathrm{K}$ added, replacing Proteinase $\mathrm{K}$ with nuclease-free water when required (Fig. 2; Table I). This was then added to the binding buffer, spike-in $+/$ - carrier molecules mix, vortexing for $10 \mathrm{sec}$. This sample lysate was then incubated at $37^{\circ} \mathrm{C}$ for $15 \mathrm{~min}$. During this time, the Maxwell ${ }^{\circledR}$ Rapid Sample Concentrator (RSC) cartridges were loaded into the RSC deck tray, their seals removed, and the RSC plungers inserted into well 8 of the cartridges. $500 \mu$ l elution tubes were loaded into the deck and $60 \mu \mathrm{l}$ nuclease-free water added to each. Ten microliters of reconstituted DNAse I was added to well 4 (yellow) of the cartridges and following incubation, all of the sample lysate was transferred into well 1 of the cartridges. The Maxwell ${ }^{\circledR}$ RSC Instrument (AS4500; Promega) (45) instrument and the 'RSC miRNA Tissue' method was used to 
Table I. Standard and optimised microRNA extraction approaches.

\begin{tabular}{|c|c|c|c|c|c|c|}
\hline Kit & Approach & Code & Plasma volume, $\mu 1$ & Proteinase $\mathrm{K}, \mu \mathrm{l}$ & $\mathrm{MS} 2, \mu \mathrm{g}$ & Glycogen, $\mu \mathrm{g}$ \\
\hline \multirow[t]{8}{*}{ Promega } & $\mathrm{S}$ & A & 500 & 60 & None & None \\
\hline & $\mathrm{O}$ & $\mathrm{B}$ & 500 & Replaced with $\mathrm{NFH}_{2} \mathrm{O}$ & None & None \\
\hline & $\mathrm{O}$ & $\mathrm{C}$ & 500 & 60 & 2.5 & None \\
\hline & $\mathrm{O}$ & $\mathrm{D}$ & 500 & Replaced with $\mathrm{NFH}_{2} \mathrm{O}$ & 2.5 & None \\
\hline & $\mathrm{O}$ & $\mathrm{E}$ & 500 & 60 & None & 5 \\
\hline & $\mathrm{O}$ & $\mathrm{F}$ & 500 & Replaced with $\mathrm{NFH}_{2} \mathrm{O}$ & None & 5 \\
\hline & $\mathrm{O}$ & G & 200 & 60 & None & None \\
\hline & $\mathrm{O}$ & $\mathrm{H}$ & 100 & 60 & None & None \\
\hline \multirow[t]{7}{*}{ Qiagen } & $\mathrm{O}$ & $\mathrm{B}$ & 200 & None & None & None \\
\hline & $\mathrm{O}$ & $\mathrm{C}$ & 200 & 24 & 1 & None \\
\hline & $\mathrm{S}$ & $\mathrm{D}$ & 200 & None & 1 & None \\
\hline & $\mathrm{O}$ & $\mathrm{E}$ & 200 & 24 & None & 2 \\
\hline & $\mathrm{O}$ & $\mathrm{F}$ & 200 & None & None & 2 \\
\hline & $\mathrm{O}$ & $\mathrm{G}$ & 200 & 24 & None & None \\
\hline & $\mathrm{O}$ & I & 100 & None & 0.5 & None \\
\hline
\end{tabular}

$\mathrm{S}$, standard approach following manufacturers' instructions/protocol as detailed in manuscript; $\mathrm{O}$, optimised approach; $\mathrm{NFH}_{2} \mathrm{O}$, nuclease-free water.

Table II. Description of the 14 miRNA primers used for reverse transcription-quantitative PCR.

\begin{tabular}{lll}
\hline miRNA primer & \multicolumn{1}{c}{ Function } & Sequence (5'-3') \\
\hline UniSp2 & RNA extraction efficiency & Unavailable \\
UniSp4 & RNA extraction efficiency & Unavailable \\
UniSp5 & RNA extraction efficiency & Unavailable \\
UniSp6 & cDNA synthesis efficiency & Unavailable \\
cel-miR-39-3p & cDNA synthesis efficiency & UCACCGGGUGUAAAUCAGCUUG \\
hsa-miR-451a & Stably expressed miRNA used for & AAACCGUUACCAUUACUGAGUU \\
hsa-miR-23a & normalisation and detection of haemolysis & \\
hsa-miR-423-3p & Stably expressed miRNA used for & AUCACAUUGCCAGGGAUUUCC \\
hsa-miR-103a-3p & normalisation and detection of haemolysis & \\
hsa-miR-191-5p & Stably expressed miRNA used for normalisation & AGCUCGGUCUGAGGCCCCUCAGU \\
hsa-miR-222-3p & Stably expressed miRNA used for normalisation & AGCAGCAUUGUACAGGGCUAUGA \\
hsa-let-7i-3p & Stably expressed miRNA used for normalisation & CAACGGAAUCCCAAAAGCAGCUG \\
hsa-miR-148-3p & Stably expressed miRNA of interest & AGCUACAUCUGGCUACUGGGU \\
hsa-miR-30e-5p & Stably expressed miRNA of interest & CUGCGCAAGCUACUGCCUUGCU \\
\hline
\end{tabular}

miRNA/miR, microRNA.

begin the automated purification run. Following processing, the eluate was stored at $-80^{\circ} \mathrm{C}$.

Five replicates were performed for each approach investigated. Extracted RNA was assessed for quality and quantity [miRNA/small RNA ratio (\%) and miRNA concentration (pg/ $\mu 1)$ ] using an Agilent Small RNA Chip (5067-1548; Agilent Technologies) and 2100 Bioanalyzer (G2939BA; Agilent Technologies) according to manufacturers' instructions.
miRNA quantification. cDNA was synthesised using the miRCURY LNA RT kit (339340; Qiagen) with a total reaction volume of $10 \mu \mathrm{l}$ and a minor modification. Specifically, during step (2), $0.5 \mu \mathrm{l}$ of UniSp6 and cel-miR-39-3p spike-in mix, (339390, RNA spike-in kit; Qiagen) (Table II) was diluted 1:5 in nuclease free water and added to the RT reaction mix. Reverse transcription-quantitative PCR (RT-qPCR) was performed using the miRCURY LNA ${ }^{\circledR} \mathrm{SYBR}^{\circledR}$ Green PCR kit (339346; Qiagen) and 14 miRNA primers (Table II). To 


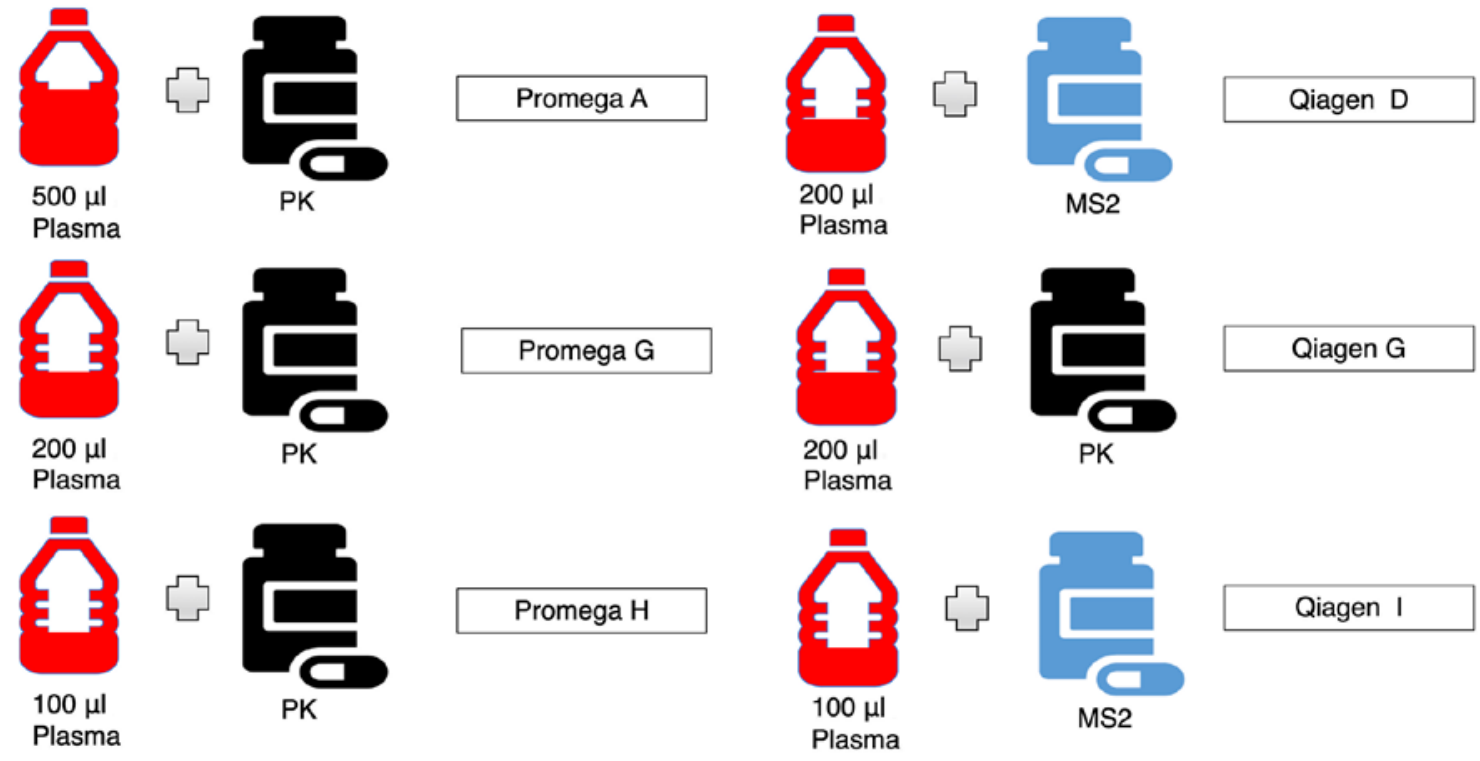

Figure 1. Pictorial scheme depicting the approaches to optimise plasma input volume. PK, proteinase K.

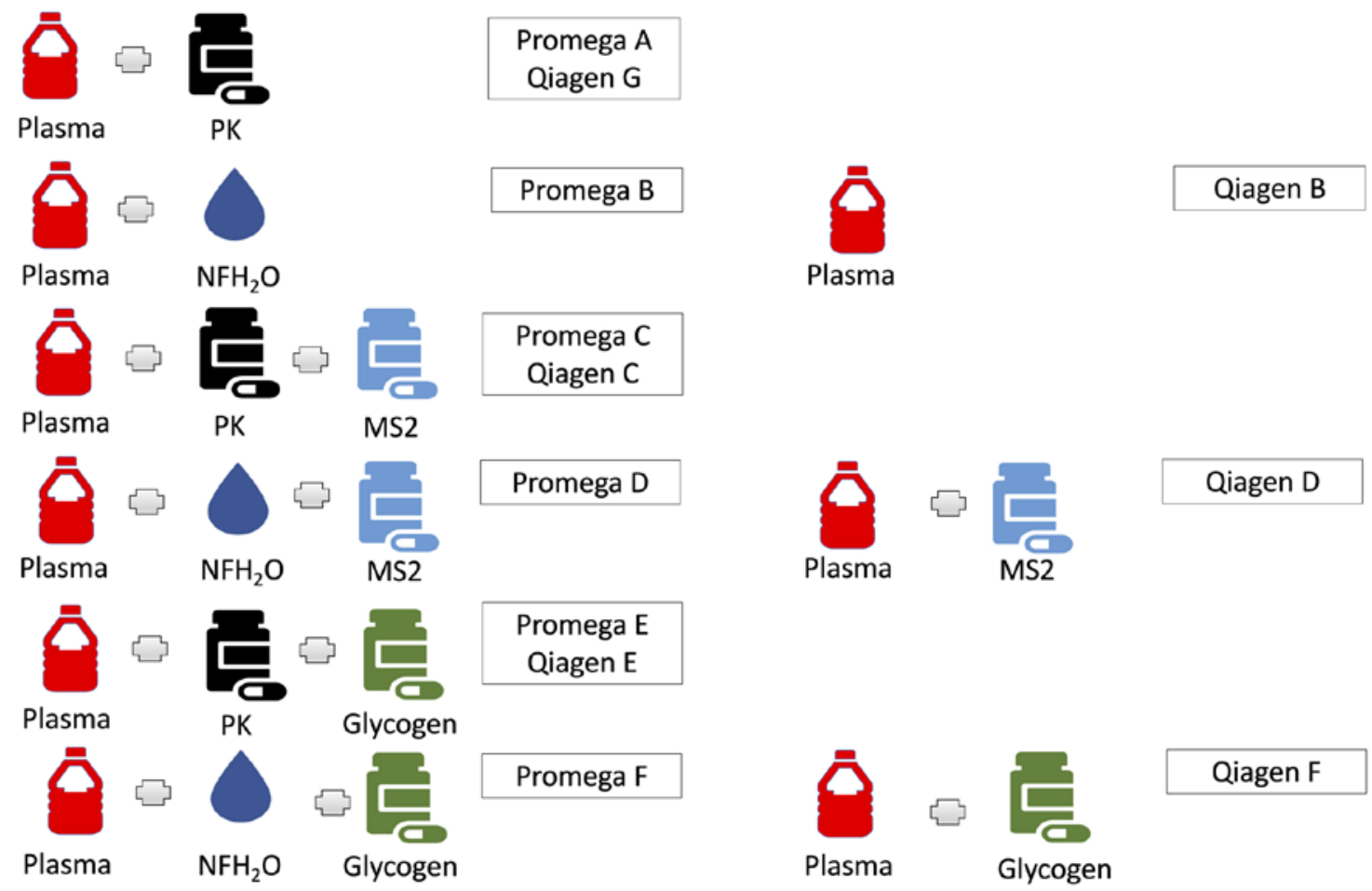

Figure 2 Pictorial scheme depicting the optimisation approaches using PK and the carriers MS2 and glycogen. PK, proteinase K.

minimise run-to-run variation, one replicate for each extraction approach (Table I) was combined with every primer in duplicate upon each 384-well plate. A 2-step cycling qPCR protocol $\left(95^{\circ} \mathrm{C}\right.$ for 2 min followed by 40 cycles at $95^{\circ} \mathrm{C}$ for $10 \mathrm{sec}$ and $56^{\circ} \mathrm{C}$ for $60 \mathrm{sec}$ ) was conducted using a Bio-Rad CFX96, Real-time C1000 Touch Thermal Cycler (Bio-Rad Laboratories, Ltd.). RT-qPCR involved no-template controls (no RNA template nor UniSp6/cel-miR-39-3p spike-ins) (NTC) run with all 14 primers and no-Reverse Transcriptase controls (NRTC) run with the hsa-miR-222-3p miRNA primer. Inhibition controls (no RNA template but
UniSp2, 4 and 5 or UniSp6/cel-miR-39-3p spike-ins added) were also prepared to exclude spike-in contamination and run with miRNA primer hsa-miR-222-3p. Replicates QG1 and QB1 run with miRNA primer hsa-miR-451 were selected as inter-plate calibrators (IPC), and performed in duplicate upon each 384-well plate.

\section{Data analysis}

Outliers. Cq values were calibrated between plates using IPC as described by TATAA (46). Mean $\mathrm{Cq}$ values and variance of duplicates performed for each extraction approach were 


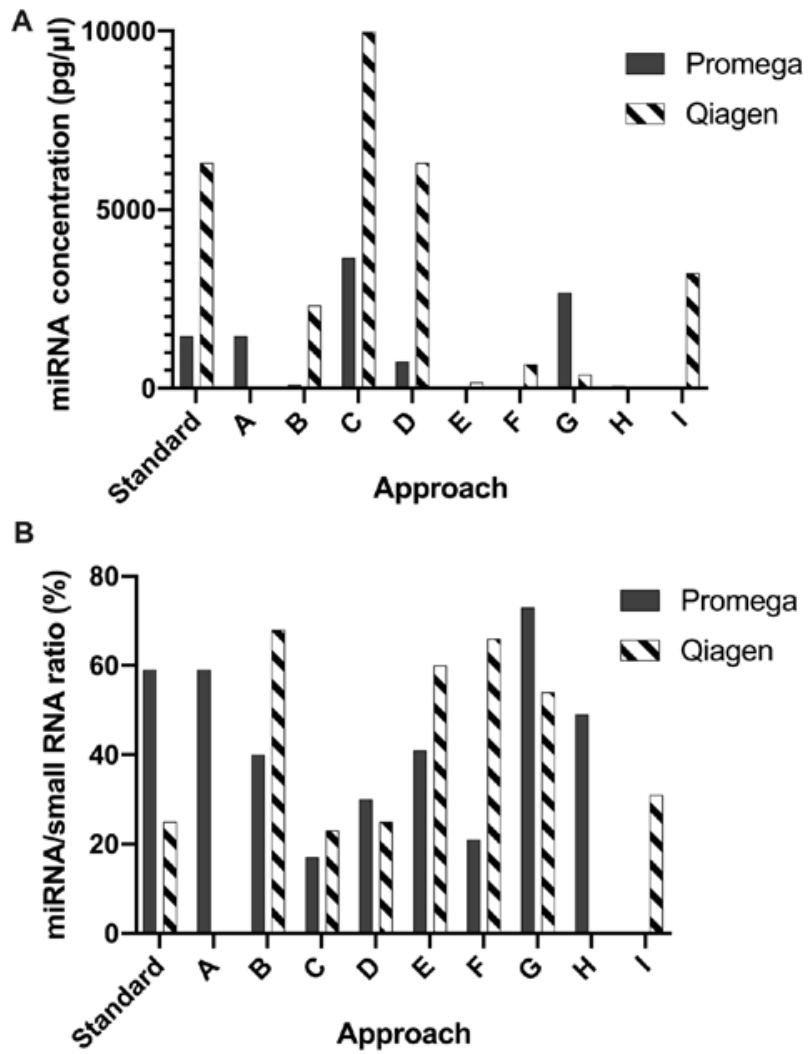

Figure 3. Bioanalyzer data measuring (A) miRNA concentration and (B) miRNA/small RNA ratio (\%) for each investigated extraction approach. miRNA, microRNA.

calculated for the 14 miRNA primers. Outliers were identified and excluded $(\mathrm{n}=25)$ based upon a PCR efficiency of 1.9 for the miRCURY LNA ${ }^{\circledR}$ SYBR $^{\circledR}$ Green PCR kit and the anticipation of increasing $\mathrm{Cq}$ variance with decreasing miRNA concentration (47) (Table III).

Quality control. RNA extraction efficiency was measured using a UniSp2, 4 and 5 spike-in mix, whereby the concentration of UniSp2>UniSp4>UniSp5 with a 100-fold magnitude change each time. Variance $<2-3$ Cqs within each dataset and $\Delta \mathrm{Cq}$ of 5-7 between spike-ins was desired. cDNA synthesis efficiency markers (UniSp6 and cel-miR-39-3p) were expected to have a target variance $<2$ Cqs. Haemolysis levels were measured by $\Delta \mathrm{Cq}=$ mean Cq hsa-miR-23a-mean Cq hsa-miR-451, whereby $\Delta \mathrm{Cq}>5$ or $>7$ indicated possible vs. high-risk of haemolysis, respectively, as guided by the manufacturer (23).

Relative expression. For each approach under investigation, normalisation was performed by calculating the geometric mean of three stably-expressed miRNAs in plasma, (hsa-miR-423-3p, hsa-miR-103a-3p and hsa-miR-191-5p). Relative quantification was based upon the $\Delta \Delta \mathrm{Cq}$ method (48), whereby the standard manufacturer's approach (A and D; Table I) was used as the control comparator for Promega and Qiagen samples respectively. Fold change was calculated by $2^{(-\Delta \Delta \mathrm{Cq})}$ and confidence intervals of $\Delta \Delta \mathrm{Cq} \log$ transformed by $2^{-(\Delta \Delta \mathrm{Cq}+/ \text {-confidence interval) }}(48)$.

Statistical analysis. Data were first checked for normality (Shapiro-Wilk test). For two-way comparisons (e.g. Bioanalyzer data), if the Gaussian distribution was satisfied, unpaired
Table III. RT-qPCR data outlier identification method.

\begin{tabular}{lc}
\hline Mean Cq of replicates & $\begin{array}{c}\text { Maximal acceptable range } \\
\text { in Cq replicates }\end{array}$ \\
\hline 25 & 0.5 \\
26 & 0.5 \\
27 & 0.5 \\
28 & 0.5 \\
29 & 0.5 \\
30 & 0.5 \\
31 & 0.5 \\
33 & 0.8 \\
34 & 1.1 \\
35 & 1.5
\end{tabular}

Data shown for RT-qPCR efficiency of 1.9 (47). RT-qPCR, reverse transcription-quantitative PCR.

t-tests with Welch's correction (due to unequal standard deviations in the populations being compared) were performed, else the Mann-Whitney U test was used. For $\geq 3$-way comparisons (e.g. comparing multiple approaches), Welch's ANOVA and post hoc Dunnett's T3 multiple comparisons test were used. Statistics were performed in GraphPad Prism version 8, with $\mathrm{P}<0.05$ deemed statistically significant.

\section{Results}

Bioanalyzer data. miRNA concentration and percentage did not significantly differ between the standardised or optimised Promega and Qiagen extraction approaches [A-I (Table I)] $(\mathrm{P}=0.09$ and $\mathrm{P}=0.94$, respectively, unpaired $t$-test with Welch's correction) (Fig. 3).

\section{qPCR data}

Quality control. Studying the Promega approaches, fold changes between the RNA extraction efficiency spike-ins were higher than desired, with UniSp4-UniSp2 of 8.05, UniSp5-UniSp4 of 5.63 (target 5-7) (Fig. 4A) and variance within the spike-ins ranging between 2.96 and $5.26 \mathrm{Cqs}$ (target $<3$ Cq) (Fig. 4B). The Qiagen approaches were generally more in range, with UniSp4-UniSp2 of 6.69, UniSp5-UniSp4 of 7.88 (target 5-7) (Fig. 4A) and variance within the spike-ins ranging between 0.72 and 1.90 Cqs (target $<3$ Cq) (Fig. 4B). In both kits, UniSp6 Cq values were higher in the NTCs compared to samples (Promega $\mathrm{P}=0.0006$; Qiagen $\mathrm{P}=0.0008$; Mann-Whitney U test) (Fig. 4C). Despite this, a comparison of the global mean UniSp6 values across all samples vs. the inhibition controls suggested that RNA inhibitors did not significantly affect the $\mathrm{PCR}$ reaction (Promega $\mathrm{P}=0.07$; Qiagen $\mathrm{P}=0.58$; Mann-Whitney U test) (Fig. 4D). This was confirmed by comparing the global mean cel-miR-39-3p values across all samples vs. cel-miR-39-3p Cq values in the inhibition controls (Promega $\mathrm{P}=0.13$; Qiagen $\mathrm{P}=0.52$; Mann-Whitney U test) (Fig. 4E). Samples were not haemolysed in any approach analysed, with all values $<7$ (Fig. 4F) (23). 


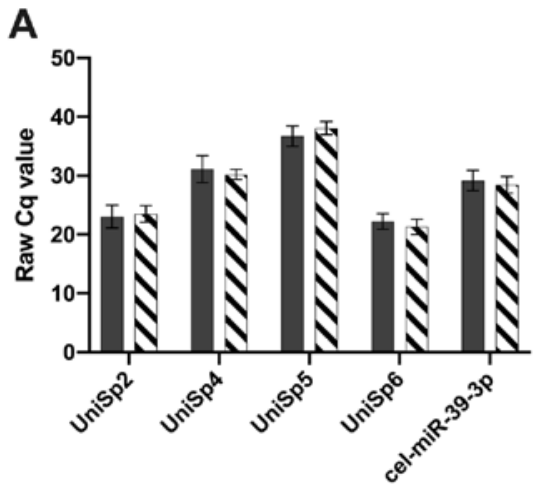

C

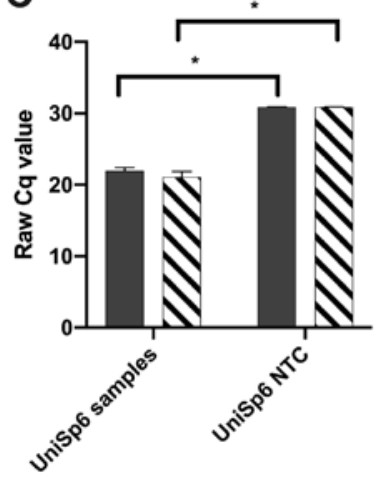

D

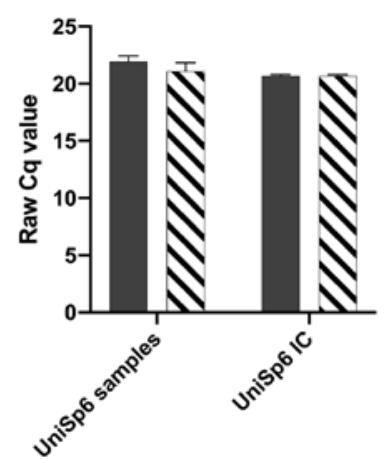

B

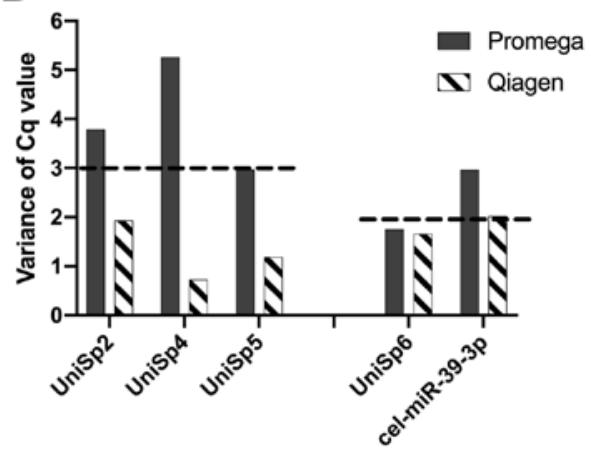

E

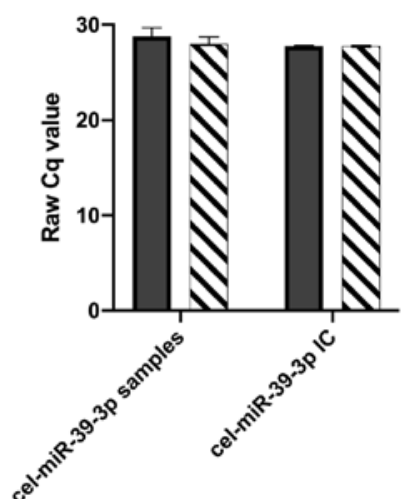

$\mathbf{F}$

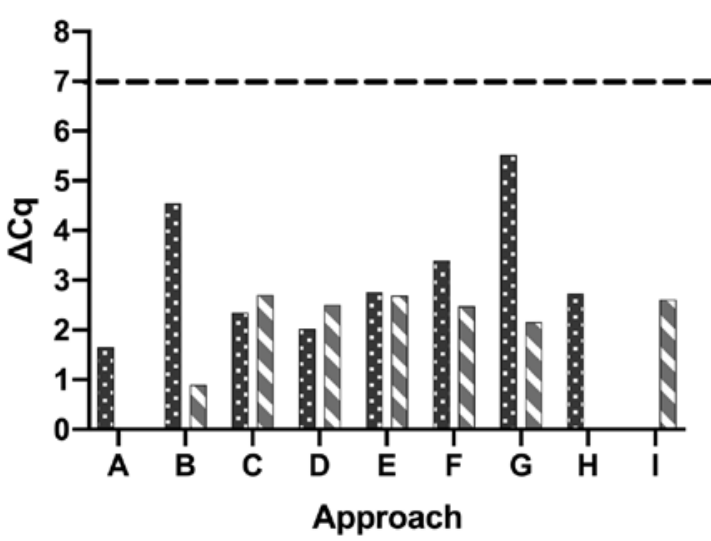

Figure 4. Quality control analysis. (A) Raw Cq values (mean \pm SD) for miRNA extraction efficiency markers (UniSp2, 4 and 5) and cDNA efficiency markers (UniSp6 and cel-miR-39-3p). A 5-7-fold $\Delta$ Cq between UniSp2-UniSp4 and UniSp4-UniSp5 was anticipated. (B) Variance of RNA extraction efficiency markers (target $<3 \mathrm{Cq}$ ) and cDNA efficiency markers (target $<2 \mathrm{Cq}$ ). (C) Comparison of raw Cq values (median + 95\% confidence interval) for global UniSp6 levels contained within samples vs. NTCs ( $\mathrm{P}=0.0006$ Promega; $\mathrm{P}=0.0008$; Qiagen; Mann-Whitney U test). (D) Comparison of raw Cq values (median + 95\% confidence interval) for global UniSp6 levels contained within samples vs. inhibition controls (Promega P=0.07; Qiagen P=0.58; Mann-Whitney U test). (E) Comparison of raw Cq values (median + 95\% confidence interval) for global cel-miR-39-3p levels contained within samples vs. inhibition controls (Promega $\mathrm{P}=0.13$; Qiagen $\mathrm{P}=0.52$; Mann-Whitney $\mathrm{U}$ test). ( $\mathrm{F}$ ) Haemolysis analysis for each approach under investigation (samples with $\Delta \mathrm{Cq}>7$ represent a high-risk of haemolysis). "P<0.05 (Mann-Whitney U test). NTC, no template control; IC, inhibition control; miRNA, microRNA.

Comparison of standard vs. optimised approaches. i) Optimisation of plasma input volume. Analysing $\Delta \Delta \mathrm{Cq}$ values across all four miRNA of interest (Table II), only one miRNA (hsa-miR-222-3p) revealed a significant difference between plasma input volumes using the Promega extraction kit (Welch's ANOVA test $\mathrm{W}=10.58, \mathrm{P}=0.02$ ). Upon post-hoc analysis, a significant difference existed between the two optimisation approaches: $200 \mu \mathrm{l}$ input + proteinase K, no carriers (approach G; Table I) vs. $100 \mu \mathrm{l}$ (+ proteinase K, no carriers, approach $\mathrm{H}$ ), $\mathrm{P}=0.02$ (Dunnett's T3 multiple comparisons test). No significant difference was found between the standard
Qiagen miRNA extraction approach using $200 \mu$ l plasma [no proteinase K + MS2, (approach D)] vs. an optimised approach using $100 \mu \mathrm{l}$ plasma [no proteinase $\mathrm{K}+\mathrm{MS} 2$, (approach I)], with $\mathrm{P}>0.05$ in all comparisons (Fig. 5).

Comparing Promega and Qiagen kits using all input volumes revealed a significant difference in only one miRNA (hsa-miR-222-3p) (Welch's ANOVA test $\mathrm{W}=6.47, \mathrm{P}=0.01$ ), with a significant post-hoc analysis for the comparison between Promega $100 \mu 1$ [+ proteinase K, no carriers, (approach $\mathrm{H}$ )] and Qiagen $200 \mu 1$ [+ proteinase K, no carriers, (approach G)] ( $\mathrm{P}=0.02$, Dunnett's T3 multiple comparisons test) (Fig. 5). 

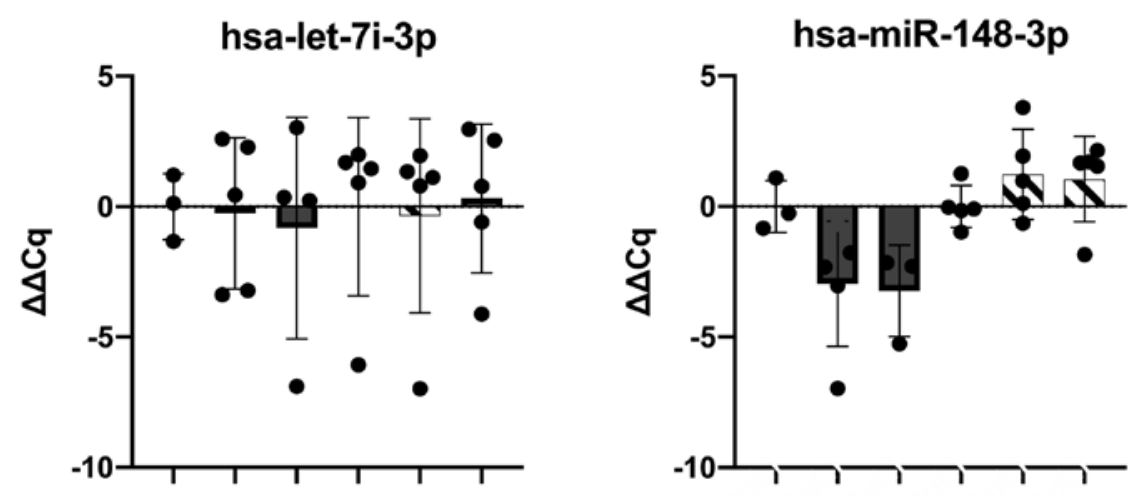

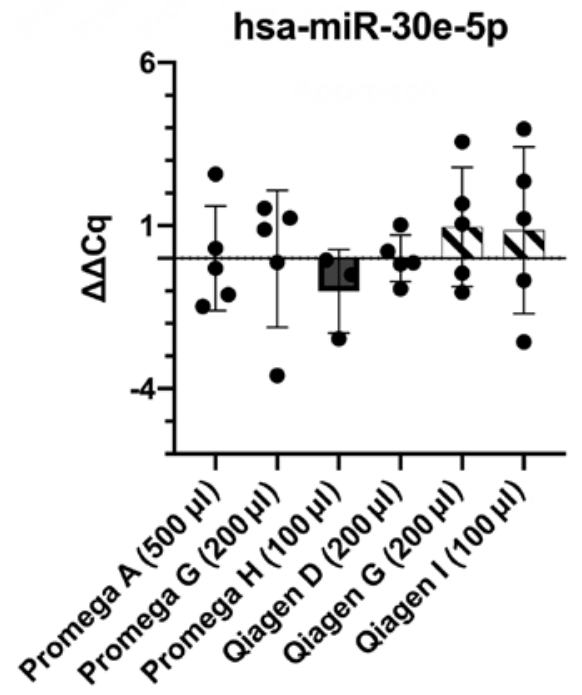

Approach

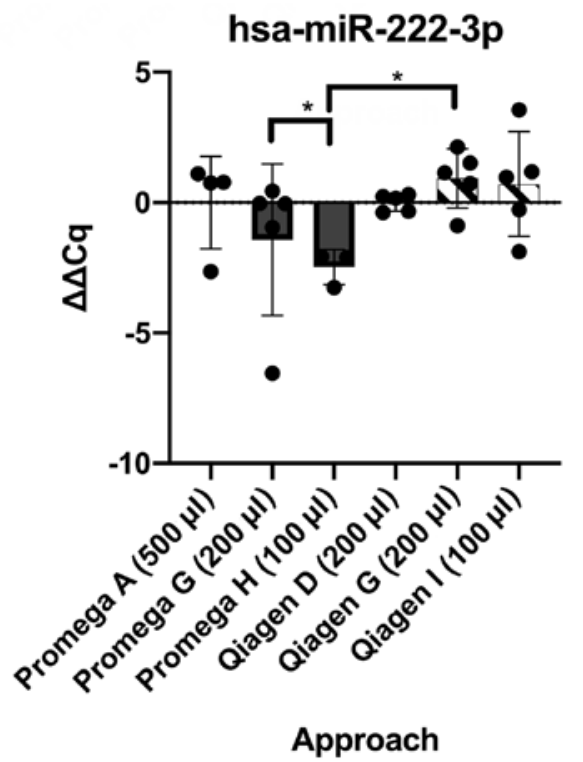

Figure 5. Effect on the four miRNAs of interest when varying the input volume of plasma (standard vs. optimised approaches) for the Promega and Qiagen miRNA extraction kits. Data are shown as the mean \pm standard deviation. " $\mathrm{P}<0.05$ (post hoc Dunnett's T3 multiple comparisons test following Welch's ANOVA). miRNA/miR, microRNA.

ii) Optimisation using Proteinase K, carriers MS2 and Glycogen. Comparing $\Delta \Delta \mathrm{Cq}$ from the standard [500 $\mu \mathrm{l}$ input + proteinase K, no carriers, (approach A)] vs. optimised approaches for the Promega kit, two miRNAs of interest showed significant changes (hsa-miR-148-3p, Welch's ANOVA test $\mathrm{W}=17.29, \mathrm{P}=0.0006$ and hsa-miR-222-3p, $\mathrm{W}=3.87$, $\mathrm{P}=0.046$ ). Using hsa-miR-148-3p, post-hoc analysis revealed a significant difference comparing approach E $(500 \mu 1$ input + proteinase $\mathrm{K}+$ Glycogen) vs. approach $\mathrm{F}$ (500 $\mu \mathrm{l}$ input, no proteinase $\mathrm{K}+$ Glycogen $)(\mathrm{P}=0.04$, Dunnett's $\mathrm{T} 3$ multiple comparisons test); and approach $\mathrm{C}$ (500 $\mu \mathrm{l}$ input + proteinase K + MS2) vs. approach $\mathrm{F}(\mathrm{P}=0.048$, Dunnett's T3 multiple comparisons test). For hsa-miR-222-3p, all post-hoc comparisons were not significant $(\mathrm{P}>0.05)$. Optimisation approaches using the Qiagen kit were not significant $(\mathrm{P}>0.05$ in all comparisons) (Fig. 6). As none of the optimisation approaches performed upon either Promega or Qiagen kits improved upon the performance of standard approaches, further comparisons between kits were not performed.

Comparison of standard approaches Promega vs. Qiagen. A comparison between $\Delta \Delta \mathrm{Cq}$ values for the Promega standard approach [500 $\mu 1$ input + proteinase $\mathrm{K}$, no carriers, (approach A)] vs. that of the Qiagen kit [200 $\mu 1$ input, no proteinase $\mathrm{K}+\mathrm{MS} 2$, (approach D)] revealed no difference in performance across the four miRNA of interest $(\mathrm{P}>0.05)$.

To determine which kit yielded more consistent RT-qPCR results, the standard deviations of the $\Delta \mathrm{Cq}$ values for each miRNA were compared, using the standard approaches for each kit. Three out of four miRNAs were significantly different (let-7i-3p, $\mathrm{P}=0.03$, hsa-miR-30e-5p, $\mathrm{P}<0.0001$, miR-222-3p, $\mathrm{P}=0.003$, unpaired t-test with Welch's correction), with higher variances observed with the Promega kit (Fig. 7).

\section{Discussion}

The literature surrounding the optimal plasma miRNA extraction kit for use in a healthy, low-risk pregnant population is extremely limited, yet pre-clinical biomarker studies continue to be published, seemingly precluding adequate investigation of this crucial preliminary step. This study, comparing standard manufacturer's methodology with attempts to optimise the efficiency of the Qiagen miRNeasy Serum/Plasma kit and the Promega Maxwell ${ }^{\circledR}$ RSC miRNA from Tissue or Plasma or Serum kit, has revealed equivalent performance across the majority of parameters investigated, including Bioanalyzer and RT-qPCR comparisons. Specifically, miRNA percentage, 
Promega proteinase K \& carrier comparison: let-7i-3p

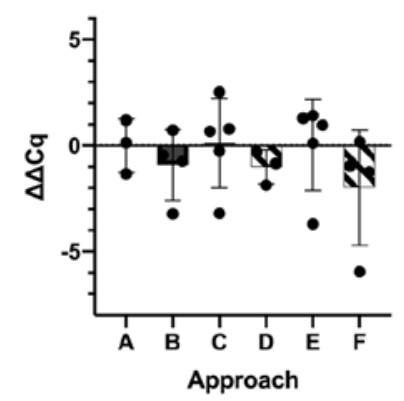

Promega proteinase K \& carrier comparison: miR-30e-5p

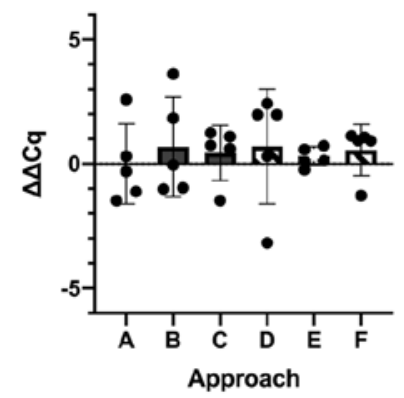

Qiagen proteinase K \& carrier comparison: let-7i-3p

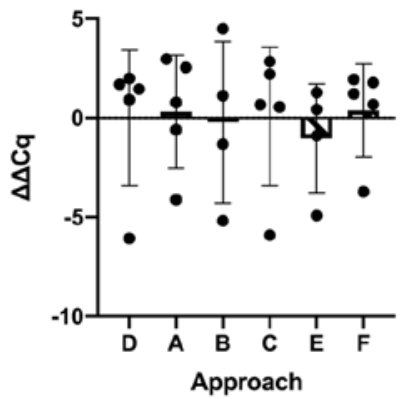

Qiagen proteinase K \& carrier comparison: miR-30e-5p

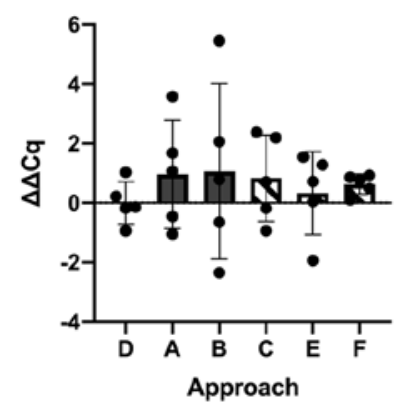

Promega proteinase K \& carrier comparison: miR-148-3p

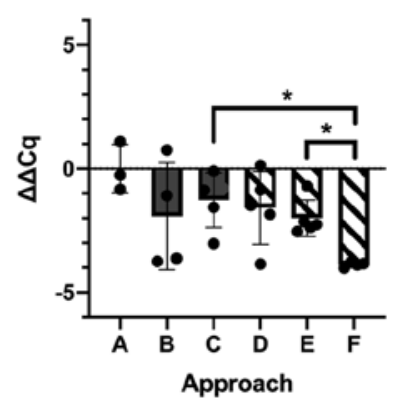

Promega proteinase K \& carrier comparison: miR-222-3p

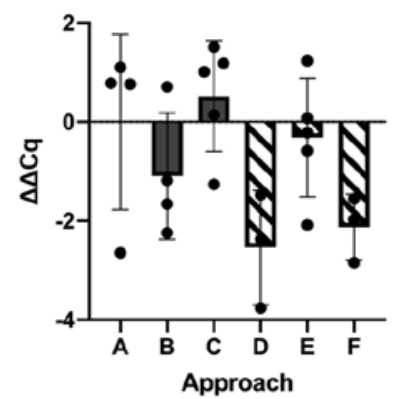

Qiagen proteinase K \& carrier comparison: miR-148-3p

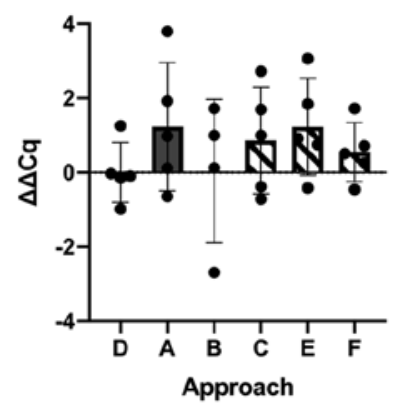

Qiagen proteinase K \& carrier comparison: miR-222-3p

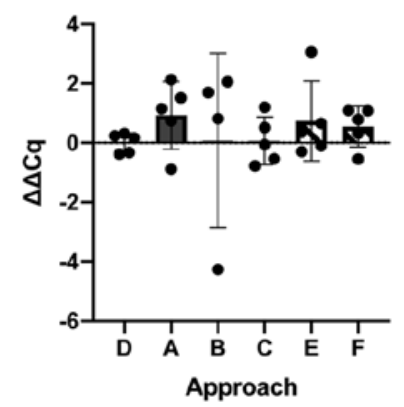

Figure 6. Impact on the four miRNAs of interest when varying the use of Proteinase K, carrier molecules MS2 and glycogen (standard vs. optimised approaches) for the Promega and Qiagen miRNA extraction kits. Data are shown as the mean \pm standard deviation. *P $<0.05$ (post hoc Dunnett's T3 multiple comparisons test following Welch's ANOVA). miRNA/miR, microRNA.

concentration and the $\Delta \Delta \mathrm{Cq}$ values of four stably expressed miRNAs of interest using RTqPCR were not significantly different when comparing the kits in terms of their standardised vs. optimised methodologies. However, a difference did emerge concerning the consistency of the two kits, with the standard Qiagen miRNeasy method producing lower $\Delta \mathrm{Cq}$ standard deviation values for three out of four miRNAs under study.
Attempts to optimise the individual performance of the Qiagen kit were conclusively unsuccessful (no miRNAs differed), whilst at first glance, this may appear less definitive for the Promega kit, with 1-2 miRNAs differing between approaches. Crucially, however, none of the optimisation approaches approved upon standard manufacturer's protocol, with differences only existing between the optimisation approaches themselves (200 vs. $100 \mu$ input 

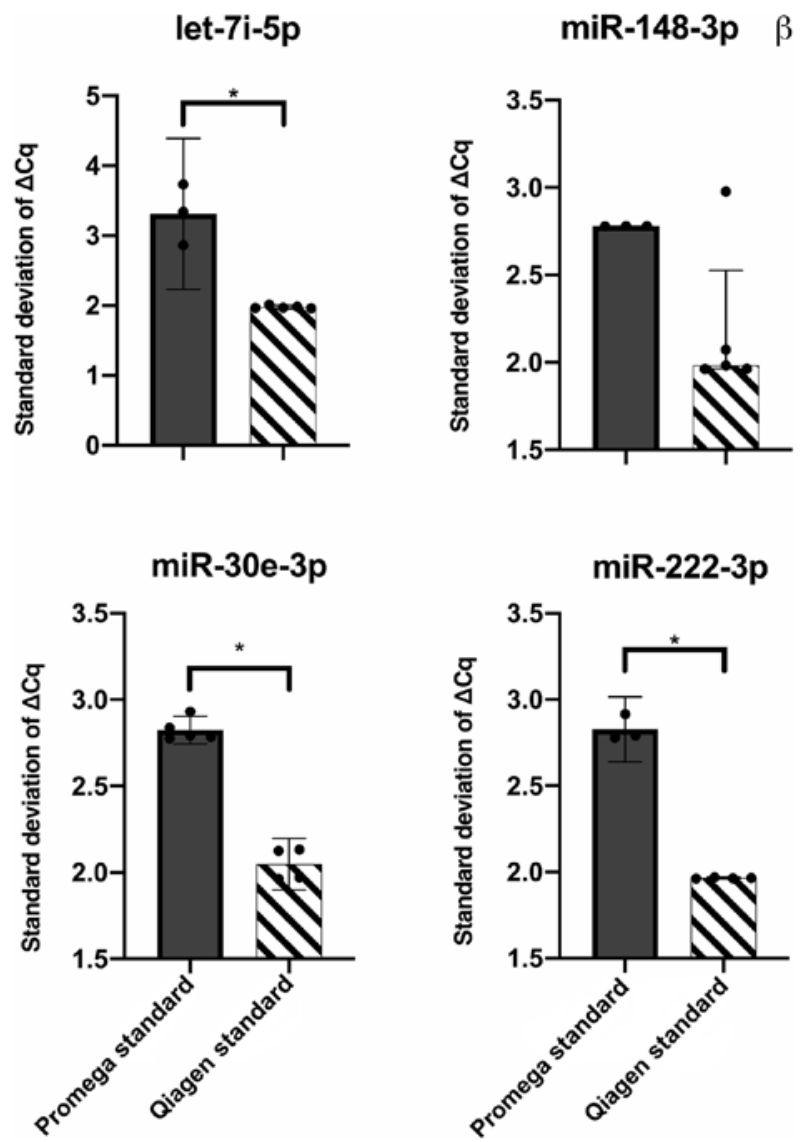

Figure 7. Consistency comparison. Comparing the $\Delta \mathrm{Cq}$ standard deviations for the Promega and Qiagen kits across the four miRNAs of interest Data are shown as the mean $+95 \%$ confidence interval except when $\beta$ then median + interquartile range (non-Gaussian distribution). $* \mathrm{P}<0.05$ (unpaired t-test with Welch's correction). miRNA/miR, microRNA.

volume; Proteinase $\mathrm{K}$ use in the presence of a glycogen carrier; or, the use of MS2 vs. glycogen). Proteinase K is a serine protease; functioning to digest native proteins within the sample, including nucleases, whilst lacking harmful DNase or RNase activity. Interestingly, subtracting this enzyme (approach B) from the standard manufacturer's approach (A), did not affect $\Delta \Delta \mathrm{Cq}$ values across the four miRNA of interest, potentially suggesting that it could be removed without adverse effect. However, given the known differences in nuclease content and sample quality, particularly when using different human samples, it would be wise to retain this step to maximize miRNA recovery. Regarding input volume for the Promega kit, lower $\Delta \Delta \mathrm{Cq}$ values were obtained using a plasma volume of 100 vs. $200 \mu 1$ for hsa-miR-222-3p, potentially suggesting that the kit performed more efficiently using lower starting volumes. However, this finding was not replicated amongst the remaining three miRNAs of interest. Previous studies using the miRNeasy biofluids kit found that doubling the input plasma volume (from 100 to $200 \mu \mathrm{l}$ ) does not equate to a proportional increase in miRNA recovery (24), due to protein clogging or saturation of the elution column, although others have failed to replicate this finding (49). It is possible that these inter-study disparities reflect the use of differing miRNA of interest and the varying ability of the kit to recover these molecules. The only way to subvert this and conclude definitively would be to use a miRNA panel, analysing many more different miRNAs simultaneously.

The unsuccessful optimisation of the standard Qiagen mIRNeasy protocol is in contrast with previously published literature using human plasma samples, suggesting that miRNA recovery was improved by carriers such as glycogen $(50)$ or yeast $(42,51)$. However, one of these studies used pig instead of human plasma for the kit optimisation experiments, failing to re-test the findings upon human samples; a precarious assumption given the known variability in media and kit performance between different species and disease states $(25,35)$. Meanwhile, others have employed the miRNeasy kit with the addition of glycogen (24) or low-dose yeast carriers (52) without first establishing whether this modification outperforms standard methodology. Furthermore, a different patient population was used within each of these studies, (patients with inflammatory bowel disease, colorectal adenomas, or healthy controls), rendering comparisons impossible.

To our knowledge this is the first published comparison of the Qiagen miRNeasy serum/plasma and Promega Maxwell ${ }^{\circledR}$ RSC miRNA from Tissue or Plasma or Serum kit. Previous literature has compared the performance of the miRNeasy serum/plasma kit to other commercially available products, finding variable results; miRNeasy yielded one of highest miRNA yields and purity $(42,53,54)$ being highly reproducible with minimal inter-operator variability (51) vs. miRNeasy outperformed $(24,52,55)$ or comparable performance $(56)$. Again, this is likely due to differences in the patient population under study (healthy vs. diseased, males vs. females of different ages), RNA input volume and the number of technical replicates performed (49), with lower number of replicates and high technical variance being associated with false significant levels (24).

The Promega extraction kit uses a new, automated paramagnetic miRNA extraction technique which confers many advantages over traditional methods, not least minimizing the risks of sample cross-contamination; safety concerns associated with the handling of chemicals such as chloroform and phenol; issues surrounding column saturation or protein clogging; and technical variability between runs. Furthermore, the approach is highly efficient and enables 16 samples to be processed simultaneously within $70 \mathrm{~min}$, which cannot be achieved using other commercially available kits (e.g. miRNeasy), largely due to protocol time limits, particularly within the column-based RNA binding, washing and elution steps. During this study, the authors could simultaneously process only 8-10 samples using the miRNeasy kit, with a processing time of $\sim 120 \mathrm{~min}$. Higher simultaneous sample processing is particularly advantageous for studies involving large sample numbers, where rapid throughput on this preliminary step is essential. Additionally, the increased elution volume using the Promega kit (60 vs. $14 \mu \mathrm{l})$ is certainly advantageous to downstream applications, enabling more experimental investigations and replicates to be conducted with each individual sample, while facilitating standardisation between experiments and batch calibration. Lower elution volumes have been suggested to generate more concentrated samples (42), however this study and others have not found this (24). A final consideration is the financial cost, with the per sample cost being slightly lower with the Promega kit ( $£ 6.88$ vs. $£ 7.80$ as of June 2020). Given the automated Promega protocol and reduced user-input, the 
increased variance of the standard methodology compared to the Qiagen kit was surprising and could represent a batch extraction issue, as these samples were extracted separately to the other optimisation approaches.

The RNA extraction efficiency spike-ins within the Promega approaches generated higher than expected $\mathrm{Cq}$ values, which could be explained by the high degree of variance introduced by the different optimisation techniques, rather than the presence of RNAse contamination. This is supported by the high variance observed within the individual spike-in data for UniSp2, 4 and 5. However, further repeat experiments, potentially involving additional purification steps would be needed to confirm or refute this. We concur that the validity of this study was not diminished by the suggestion of cDNA synthesis inhibitors within the quality control analysis. Firstly, these inhibitors did not significantly impair the RT-qPCR upon statistical analysis and secondly, such quality control indicators are designed for samples extracted using the same standardised methodology, which was not the case in this study. It is clear that some optimisation approaches (e.g. $\mathrm{H}$ in Promega), were detrimental to miRNA extraction, generating $\mathrm{Cq}$ values $>40$ and hence the return of 'no data' for several replicates, which would have raised the variance of the quality control markers. The same applies for the RNA extraction quality control spike-ins. A limitation of this study is that a like-for-like comparison could not be made using the automated miRNA extraction system manufactured by Qiagen; (QIAcube, 9001793), and further studies should address this. Given the inter-individual variation within human samples (57), further work should include repeating these experiments using samples taken from several individuals to validate the findings. The equivalent performance of the two extraction kits sampled within this study, suggests that either would be suitable when evaluating or setting up studies concerning the miRNA profile of healthy pregnant women.

\section{Acknowledgements}

Not applicable.

\section{Funding}

VLP's salary as a Clinical Research Fellow and the laboratory consumables within the present study were funded by two large grants (grant nos. CA154 and CA184) from Weston Park Cancer Charity, Sheffield, UK.

\section{Availability of data and materials}

The datasets used and/or analysed during the current study are available from the corresponding author on reasonable request.

\section{Authors' contributions}

VLP was involved in study conceptualization, data curation, methodology, project administration, formal analysis, funding acquisition, visualization and original draft preparation, and provided resources. BFC was involved in acquisition of data, methodology and original draft preparation. VLP and BFC confirmed the authenticity of the raw data. EG and BM were involved in acquisition of data, methodology and formal analysis. SW was involved in acquisition of data, methodology, resources, and supervision of the laboratory and writing. AP and PRH developed the methodology, provided resources, supervised the study, and reviewed and edited the manuscript. All authors read and approved the final manuscript.

\section{Ethics approval and consent to participate}

Ethics approval was obtained from the North East Newcastle and North Tyneside 1 NHS Research Ethics Committee, UK, reference 16/NE/0292. Written consent was taken from all participants.

\section{Patient consent for publication}

Covered within the ethics application 16/N3/0292. No patient identifiable information is presented within the manuscript.

\section{Competing interests}

The authors declare that they have no competing interests.

\section{References}

1. Hobert O: Gene regulation by transcription factors and microRNAs. Science 319: 1785-1786, 2008.

2. Croce CM and Calin GA: miRNAs, cancer, and stem cell division. Cell 122: 6-7, 2005.

3. Hammond SM: An overview of microRNAs. Adv Drug Deliv Rev 87: 3-14, 2015.

4. He L, Thomson JM, Hemann MT, Hernando-Monge E, Mu D, Goodson S, Powers S, Cordon-Cardo C, Lowe SW, Hannon GJ, et al: A microRNA polycistron as a potential human oncogene. Nature 435: 828-833, 2005.

5. Alrob OA, Khatib S and Naser SA: MicroRNAs 33, 122, and 208: A potential novel targets in the treatment of obesity, diabetes, and heart-related diseases. J Physiol Biochem 73: 307-314, 2017.

6. Creemers EE, Tijsen AJ and Pinto YM: Circulating microRNAs: Novel biomarkers and extracellular communicators in cardiovascular disease? Circ Res 110: 483-495, 2012.

7. Chen X, Ba Y, Ma L, Cai X, Yin Y, Wang K, Guo J, Zhang Y, Chen J, Guo X, et al: Characterization of microRNAs in serum: A novel class of biomarkers for diagnosis of cancer and other diseases. Cell Res 18: 997-1006, 2008.

8. Fayyad-Kazan H, Bitar N, Najar M, Lewalle P, Fayyad-Kazan M, Badran R, Hamade E, Daher A, Hussein N, ElDirani R, et al: Circulating miR-150 and miR-342 in plasma are novel potential biomarkers for acute myeloid leukemia. J Transl Med 11: 31, 2013.

9. Rossbach M: Therapeutic implications of microRNAs in human cancer. J Nucleic Acids Investig: Feb 2, 2011 (Epub ahead of print). doi: 10.4081/jnai.2011.2200.

10. Mishra PJ: MicroRNAs as promising biomarkers in cancer diagnostics. Biomark Res 2: 19, 2014.

11. Cai M, Kolluru GK and Ahmed A: Small molecule, big prospects: MicroRNA in pregnancy and its complications. J Pregnancy 2017: 6972732, 2017.

12. Morales-Prieto DM, Ospina-Prieto S, Chaiwangyen W, Schoenleben $M$ and Markert UR: Pregnancy-associated miRNA-clusters. J Reprod Immunol 97: 51-61, 2013.

13. Morales Prieto DM and Markert UR: MicroRNAs in pregnancy. J Reprod Immunol 88: 106-111, 2011.

14. Gilad S, Meiri E, Yogev Y,Benjamin S,Lebanony D, Yerushalmi N, Benjamin H, Kushnir M, Cholakh H, Melamed N, et al: Serum microRNAs are promising novel biomarkers. PLoS One 3: e3148, 2008.

15. Kotlabova K, Doucha $\mathbf{J}$ and Hromadnikova I: Placental-specific microRNA in maternal circulation - identification of appropriate pregnancy-associated microRNAs with diagnostic potential. J Reprod Immunol 89: 185-191, 2011.

16. Chim SS, Shing TK, Hung EC, Leung TY, Lau TK, Chiu RW and Lo YM: Detection and characterization of placental microRNAs in maternal plasma. Clin Chem 54: 482-490, 2008. 
17. Hromadnikova I, Kotlabova K, Ivankova K, Vedmetskaya Y and Krofta L: Profiling of cardiovascular and cerebrovascular disease associated microRNA expression in umbilical cord blood in gestational hypertension, preeclampsia and fetal growth restriction. Int J Cardiol 249: 402-409, 2017.

18. Hromadnikova I, Dvorakova L, Kotlabova K and Krofta L: The Prediction of gestational hypertension, preeclampsia and fetal growth restriction via the first trimester screening of plasma exosomal C19MC microRNAs. Int J Mol Sci 20: 2972, 2019.

19. Sheikh AM, Small HY, Currie G and Delles C: Systematic review of micro-RNA expression in pre-eclampsia identifies a number of common pathways associated with the disease. PLoS One 11: e0160808, 2016.

20. Zhu Y, Tian F, Li H, Zhou Y, Lu J and Ge Q: Profiling maternal plasma microRNA expression in early pregnancy to predict gestational diabetes mellitus. Int J Gynaecol Obstet 130: 49-53, 2015.

21. Zhao C, Dong J, Jiang T, Shi Z, Yu B, Zhu Y, Chen D, Xu J, Huo R, Dai J, et al: Early second-trimester serum miRNA profiling predicts gestational diabetes mellitus. PLoS One 6 : e23925, 2011.

22. Yu Z, Han S, Hu P, Zhu C, Wang X, Qian L and Guo X: Potential role of maternal serum microRNAs as a biomarker for fetal congenital heart defects. Med Hypotheses 76: 424-426, 2011.

23. Blondal T, Jensby Nielsen S, Baker A, Andreasen D, Mouritzen P Wrang Teilum M and Dahlsveen IK: Assessing sample and miRNA profile quality in serum and plasma or other biofluids. Methods 59: S1-S6, 2013

24. McAlexander MA, Phillips MJ and Witwer KW: Comparison of methods for miRNA extraction from plasma and quantitative recovery of RNA from cerebrospinal fluid. Front Genet 4: 83, 2013.

25. Ge Q, Shen Y, Tian F, Lu J, Bai Y and Lu Z: Profiling circulating microRNAs in maternal serum and plasma. Mol Med Rep 12: 3323-3330, 2015

26. Glinge C, Clauss S, Boddum K, Jabbari R, Jabbari J, Risgaard B, Tomsits P, Hildebrand B, Kääb S, Wakili R, et al: Stability of circulating blood-based MicroRNAs - pre-analytic methodological considerations. PLoS One 12: e0167969, 2017.

27. Brunet-Vega A, Pericay C, Quílez ME, Ramírez-Lázaro MJ, Calvet $\mathrm{X}$ and Lario S: Variability in microRNA recovery from plasma: Comparison of five commercial kits. Anal Biochem 488: 28-35, 2015.

28. Avissar-Whiting M, Veiga KR, Uhl KM, Maccani MA, Gagne LA, Moen EL and Marsit CJ: Bisphenol A exposure leads to specific microRNA alterations in placental cells. Reprod Toxicol 29: 401-406, 2010.

29. Maccani MA, Avissar-Whiting M, Banister CE, McGonnigal B Padbury JF and Marsit CJ: Maternal cigarette smoking during pregnancy is associated with downregulation of miR-16, miR-21, and miR-146a in the placenta. Epigenetics 5: 583-589, 2010.

30. Wang K, Yuan Y, Cho JH, McClarty S, Baxter D and Galas DJ: Comparing the MicroRNA spectrum between serum and plasma. PLoS One 7: e41561, 2012.

31. Ban E, Chae DK, Yoo YS and Song EJ: An improvement of miRNA extraction efficiency in human plasma. Anal Bioanal Chem 409: 6397-6404, 2017.

32. Tiberio P, Callari M, Angeloni V, Daidone MG and Appierto V: Challenges in using circulating miRNAs as cancer biomarkers. BioMed Res Int 2015: 731479, 2015.

33. McDonald JS, Milosevic D, Reddi HV, Grebe SK and Algeciras-Schimnich A: Analysis of circulating microRNA: Preanalytical and analytical challenges. Clin Chem 57: 833-840, 2011.

34. Feng X, Liu Y and Wan N: Plasma microRNA detection standardization test. J Clin Lab Anal 34: e23058, 2020.

35. Foye C, Yan IK, David W, Shukla N, Habboush Y, Chase L, Ryland K, Kesari V and Patel T: Comparison of miRNA quantitation by Nanostring in serum and plasma samples. PLoS One 12: e0189165, 2017

36. Moldovan L, Batte KE, Trgovcich J, Wisler J, Marsh CB and Piper M: Methodological challenges in utilizing miRNAs as circulating biomarkers. J Cell Mol Med 18: 371-390, 2014.

37. Kloten V, Neumann MHD, Di Pasquale F, Sprenger-Haussels M, Shaffer JM, Schlumpberger M, Herdean A, Betsou F, Ammerlaan W, Af Hällström T, et al; CANCER-ID consortium: Multicenter evaluation of circulating plasma MicroRNA extraction technologies for the development of clinically feasible reverse transcription quantitative PCR and next-generation sequencing analytical work Flows. Clin Chem 65: 1132-1140, 2019.
38. Qiagen: miRCURY LNA miRNA PCR - Exosomes, serum/plasma and other biofluid samples handbook. 2017. https://www.qiagen. $\mathrm{com} /$ fi/resources/resourcedetail?id=7ab5f614-f5d6-4bdc-b22b$246 \mathrm{ec} 3601588 \&$ lang $=\mathrm{en}$

39. Andreasen D, Fog JU, Biggs W, Salomon J, Dahslveen IK, Baker A and Mouritzen P: Improved microRNA quantification in total RNA from clinical samples. Methods 50: S6-S9, 2010.

40. Ramón-Núñez LA, Martos L, Fernández-Pardo A, Oto J, Medina P, España F and Navarro S: Comparison of protocols and RNA carriers for plasma miRNA isolation. Unraveling RNA carrier influence on miRNA isolation. PLoS One 12: e0187005, 2017.

41. Danielson KM, Rubio R, Abderazzaq F, Das S and Wang YE: High throughput sequencing of extracellular RNA from human plasma. PLoS One 12: e0164644, 2017.

42. Moret I, Sánchez-Izquierdo D, Iborra M, Tortosa L, Navarro-Puche A, Nos P, Cervera J and Beltrán B: Assessing an improved protocol for plasma microRNA extraction. PLoS One 8: e82753, 2013

43. Gautam A, Kumar R, Dimitrov G, Hoke A, Hammamieh R and Jett M: Identification of extracellular miRNA in archived serum samples by next-generation sequencing from RNA extracted using multiple methods. Mol Biol Rep 43: 1165-1178, 2016.

44. Promega: Maxwell ${ }^{\circledR}$ RSC miRNA Plasma and Serum Kit: Instructions for Use of Product AS1680. https://www.promega. co.uk/products/nucleic-acid-extraction/rna/maxwell-rscmirnatissue-plasma-serum-kit/?catNum=AS1460\#protocols.

45. Promega: Maxwell ${ }^{\circledR}$ RSC Instrument, AS4500. https://www. promega.co.uk/products/lab-automation/maxwell-instruments/ maxwell-rsc-instrument/?catNum=AS4500

46. Interplate Calibrator, Inter-run variation compensation, SYBR Protocol. TATAA Biocenter AB, Göteborg, 2017.

47. de Ronde MW, Ruijter JM, Lanfear D, Bayes-Genis A, Kok MG, Creemers EE, Pinto YM and Pinto-Sietsma SJ: Practical data handling pipeline improves performance of qPCR-based circulating miRNA measurements. RNA 23: 811-821, 2017.

48. Livak KJ and Schmittgen TD: Analysis of relative gene expression data using real-time quantitative PCR and the 2(-Delta Delta C(T)) method. Methods 25: 402-408, 2001

49. El-Khoury V, Pierson S, Kaoma T, Bernardin F and Berchem G: Assessing cellular and circulating miRNA recovery: The impact of the RNA isolation method and the quantity of input material. Sci Rep: Jan 20, 2016 (Epub ahead of print). doi: org/10.1038/srep19529.

50. Ford KL, Anwar M, Heys R, Ahmed EM, Caputo M, Game L, Reeves BC, Punjabi PP, Angelini GD, Petretto E, et al: Optimisation of laboratory methods for whole transcriptomic RNA analyses in human left ventricular biopsies and blood samples of clinical relevance. PLoS One 14: e0213685, 2019.

51. Rice J, Roberts H, Burton J, Pan J, States V, Rai SN and Galandiuk S: Assay reproducibility in clinical studies of plasma miRNA. PLoS One 10: e0121948, 2015.

52. Wong RK, MacMahon M, Woodside JV and Simpson DA: A comparison of RNA extraction and sequencing protocols for detection of small RNAs in plasma. BMC Genomics 20: 446, 2019.

53. Meerson A and Ploug T: Assessment of six commercial plasma small RNA isolation kits using qRT-PCR and electrophoretic separation: higher recovery of microRNA following ultracentrifugation. Biol Methods Protoc 1: bpw003, 2016.

54. Burgos KL, Javaherian A, Bomprezzi R, Ghaffari L, Rhodes S, Courtright A, Tembe W, Kim S, Metpally R and Van KeurenJensen $\mathrm{K}$ : Identification of extracellular miRNA in human cerebrospinal fluid by next-generation sequencing. RNA 19: 712-722, 2013.

55. Guo Y, Vickers K, Xiong Y, Zhao S, Sheng Q, Zhang P, Zhou W and Flynn CR: Comprehensive evaluation of extracellular small RNA isolation methods from serum in high throughput sequencing. BMC Genomics 18: 50, 2017.

56. Tan GW, Khoo AS and Tan LP: Evaluation of extraction kits and RT-qPCR systems adapted to high-throughput platform for circulating miRNAs. Sci Rep 5: 9430, 2015.

57. Keller A, Rounge T, Backes C, Ludwig N, Gislefoss R, Leidinger P, Langseth $\mathrm{H}$ and Meese E: Sources to variability in circulating human miRNA signatures. RNA Biol 14: 1791-1798, 2017.

This work is licensed under a Creative Commons Attribution-NonCommercial-NoDerivatives 4.0 International (CC BY-NC-ND 4.0) License. 